\title{
Commentary: Aiming for Study Comparability in Parkinson's Disease: Proposal for a Modular Set of Biomarker Assessments to be Used in Longitudinal Studies
}

\author{
Yassar Alamri ${ }^{*}$, Michael MacAskill and Tim Anderson \\ Department of Medicine, University of Otago, Christchurch, New Zealand \\ Keywords: dementia, Parkinson disease, cohort studies, markers, harmonization
}

\section{A commentary on}

Aiming for Study Comparability in Parkinson's Disease: Proposal for a Modular Set of Biomarker Assessments to be Used in Longitudinal Studies

by Lerche, S., Heinzel, S., Alves, G. W., Barone, P., Behnke, S., Ben-Shlomo, Y., et al. (2016). Front. Aging Neurosci. 8:121. doi: 10.3389/fnagi.2016.00121

\section{OPEN ACCESS}

Edited by:

Milica S. Prostran,

University of Belgrade, Serbia

Reviewed by:

Nevena Divac,

University of Belgrade, Serbia

${ }^{*}$ Correspondence:

Yassar Alamri

yassar.alamri@nzbri.org

Received: 21 August 2016 Accepted: 19 December 2016

Published: 09 January 2017

Citation:

Alamri Y, MacAskill M and Anderson T (2017) Commentary: Aiming for Study

Comparability in Parkinson's Disease:

Proposal for a Modular Set of

Biomarker Assessments to be Used in

Longitudinal Studies.

Front. Aging Neurosci. 8:331.

doi: 10.3389/fnagi.2016.00331

\section{INTRODUCTION}

We read the conclusions of Lerche et al. (2016) with great interest. Various definitions exist in the literature for biological markers (often shortened to biomarkers). In medicine, a biomarker may refer to an indicator based upon which an inference about the person's health can be made. The National Health Institute's Biomarkers Definitions Working Group (Biomarkers Definitions Working Group, 2001) defines a biomarker as "a characteristic that is objectively measured and evaluated as an indicator of normal biological processes, pathogenic processes or pharmacological responses to a therapeutic intervention.”

Despite the recent interest in finding biomarkers for Parkinson's disease (PD; as evident from the number of "Parkinson's disease biomarker" articles indexed by the MEDLINE ${ }^{\circledR}$ Database; see Figure 1), an acceptable biomarker for PD remains to be elusive. Given the complexity underpinning PD's pathological processes, a useful single biomarker is unlikely to encompass the plethora of disease facets. However, the diverse features of PD's aetiological process and manifestations lend it particularly suited to have a number of biomarkers (of different categories and types) that serve distinct purposes at various stages of the disease.

\section{CHALLENGES FACING PD BIOMARKER RESEARCH}

As with other neurodegenerative disorders, several hurdles face biomarker discovery in PD. Such challenges include the general complexity of the human CNS, limited access and availability of tissue for histological diagnosis during the patient's lifetime and the restricted number of clinical end-points and the lack of validation models for present ones (Dunckley et al., 2005). 


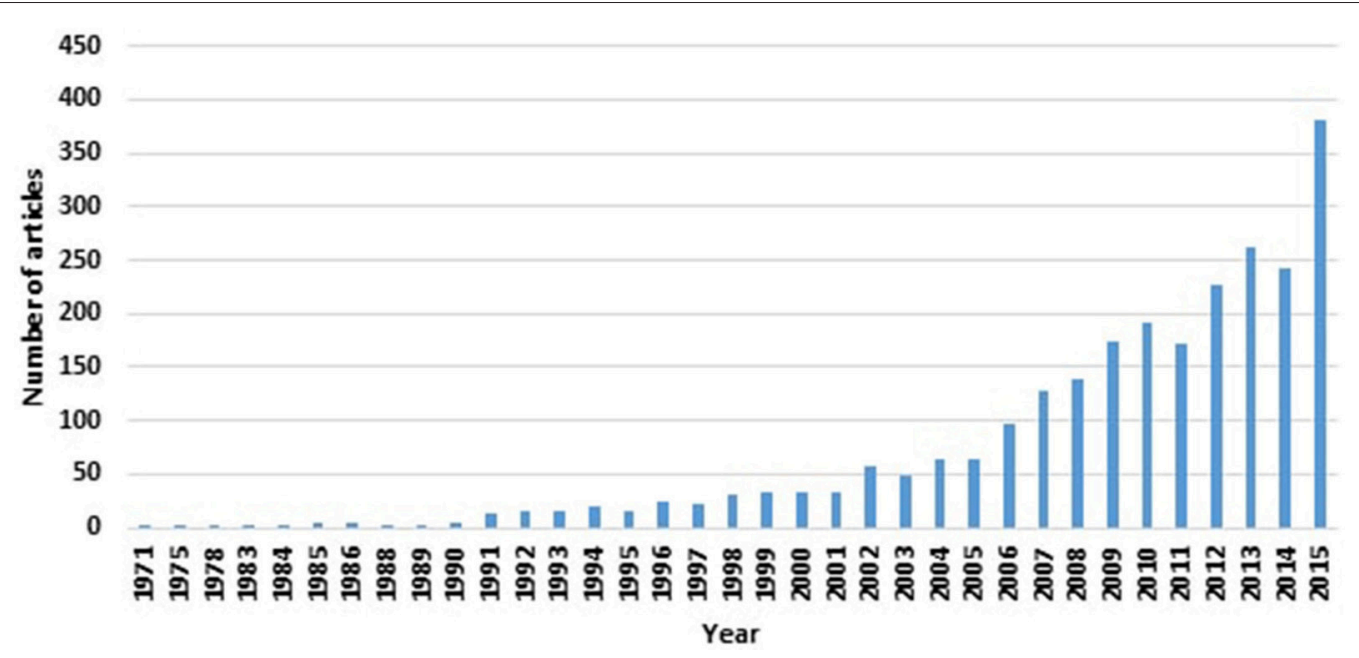

FIGURE 1 | Increasing numbers of PD biomarker-related articles, as indexed by MEDLINE ${ }^{\circledR}$ as of January 2016 , are appearing in the literature.

Added to these general obstacles are the diagnostic uncertainties surrounding $\mathrm{PD}$, including disease heterogeneity and the potential for atypical parkinsonian syndromes.

The multiplicity of disease aspects of PD make it difficult for a single all-purpose biomarker to ever exist. This is evident from the current lack of such a "Holy Grail" biomarker to date. By the same token, "reductionist"-type biomarkers focusing on single aspects of PD molecular neuropathology are unlikely to be overly clinically useful in the general schema of disease (Mielke and Maetzler, 2014). It seems, therefore, that several biomarkers of different types may be utilized in conjunction to identify the person's disease stage.

Taking PD diagnosis as an example, no one single biomarker to date has demonstrated perfect sensitivity and specificity; even post-mortem pathological examinations can be inconclusive at times (Lees et al., 2009; Berg et al., 2013). Instead, the suggested tier-based system of different types of biomarkers (e.g., clinical assessment by a specialist, biofluid analysis, genetic testing and/or imaging studies) used in concert is much more likely to yield much needed diagnostic accuracy (Streffer et al., 2012; Schlossmacher and Mollenhauer, 2014).

\section{REFERENCES}

Abbott, R. D., Ross, G. W., Petrovitch, H., Masaki, K. H., Launer, L. J., Nelson, J. S., et al. (2016). Midlife milk consumption and substantia nigra neuron density at death. Neurology 86, 512-519. doi: 10.1212/WNL.0000000000 002254

Azuaje, F. (2011). Bioinformatics and Biomarker Discovery: 'Omic' Data Analysis for Personalized Medicine. West Sussex: John Wiley and Sons.

Berg, D., Lang, A. E., Postuma, R. B., Maetzler, W., Deuschl, G., Gasser, T., et al. (2013). Changing the research criteria for the diagnosis of Parkinson's disease: obstacles and opportunities. Lancet Neurol. 12, 514-524. doi: 10.1016/S1474-4422(13)70047-4

\section{FUTURE DIRECTIONS}

Much research has gone into obtaining new prospectivelycollected data (e.g., The Parkinson Progression Marker Initiative Marek, 2011), as well as examining archived biofluid and tissue specimens [e.g., Honolulu Asian Aging Study (Abbott et al., 2016)]. However, much still remains to be desired.

The ongoing collaborative efforts are hoped to generate large datasets and standardized resources which are publicly available. The next major step is the proper utilization of such data mines. This would involve using current bioinformatics and technological advances (i.e., -omics) to thoroughly evaluate the data, as well as making use of integration models which can capture interplay between biomarkers that would have otherwise been hidden (Azuaje, 2011).

\section{AUTHOR CONTRIBUTIONS}

Study concept and design: YA, TA, and MM; Acquisition of data: YA; Analysis and interpretation: YA, MM; Critical revision of manuscript: YA, TA, and MM; Study supervision: TA, MM.

Biomarkers Definitions Working Group (2001). Biomarkers and surrogate endpoints: preferred definitions and conceptual framework. Clin Pharmacol Ther. 69, 89-95. doi: 10.1067/mcp.2001.113989

Dunckley, T., Coon, K. D., and Stephan, D. A. (2005). Discovery and development of biomarkers of neurological disease. Drug Discov. Today 10, 326-334. doi: 10.1016/S1359-6446(04)03353-7

Lees, A. J., Hardy, J., and Revesz, T. (2009). Parkinson's disease. Lancet. 373, 2055-2066. doi: 10.1016/S0140-6736(09)60492-X

Lerche, S., Heinzel, S., Alves, G. W., Barone, P., Behnke, S., Ben-Shlomo, Y., et al. (2016). Aiming for study comparability in parkinson's disease: proposal for a modular set of biomarker assessments to be used in longitudinal studies. Front. Aging Neurosci. 8:121. doi: 10.3389/fnagi.2016.00121 
Marek, K. (2011). PPMI collaborators. the parkinson progression marker initiative (PPMI). Prog. Neurobiol. 95, 629-635. doi: 10.1016/j.pneurobio.2011. 09.005

Mielke, M. M., and Maetzler, W. (2014). A 'bird's eye' view on the current status and potential benefits of blood biomarkers for Parkinson's disease. Biomark Med. 8, 225-227. doi: 10.2217/bmm. 13.139

Schlossmacher, M. G., and Mollenhauer, B. (2014). Biomarker research in Parkinson's disease: objective measures needed for patient stratification in future cause-directed trials. Biomark Med. 4, 647-50. doi: 10.2217/bmm.10.93

Streffer, J. R., Grachev, I. D., Fitzer-Attas, C., Gomez-Mancilla, B., Boroojerdi, B., Bronzova, J., et al. (2012). Prerequisites to launch neuroprotective trials in Parkinson's disease: an industry perspective. Mov. Disord. 27, 651-655. doi: $10.1002 / \mathrm{mds} .25017$
Conflict of Interest Statement: The authors declare that the research was conducted in the absence of any commercial or financial relationships that could be construed as a potential conflict of interest.

The reviewer ND and handling Editor declared their shared affiliation, and the handling Editor states that the process nevertheless met the standards of a fair and objective review.

Copyright (c) 2017 Alamri, MacAskill and Anderson. This is an open-access article distributed under the terms of the Creative Commons Attribution License (CC BY). The use, distribution or reproduction in other forums is permitted, provided the original author(s) or licensor are credited and that the original publication in this journal is cited, in accordance with accepted academic practice. No use, distribution or reproduction is permitted which does not comply with these terms. 